\title{
Simple and Rapid Synthesis of $\alpha-\mathrm{Fe}_{2} \mathrm{O}_{3}$ Nanowires Under Ambient Conditions
}

\author{
Albert G. Nasibulin ${ }^{1}(\varangle)$, Simas Rackauskas ${ }^{1}$, Hua Jiang ${ }^{1}$, Ying Tian ${ }^{1}$, Prasantha Reddy Mudimela', \\ Sergey D. Shandakov ${ }^{1,2}$, Larisa I . Nasibulina ${ }^{1}$, Jani Sainio ${ }^{3}$, and Esko I. Kauppinen ${ }^{1,4}(\bowtie)$ \\ ${ }^{1}$ NanoMaterials Group, Department of Applied Physics and Center for New Materials, Helsinki University of Technology, \\ Puumiehenkuja 2, 02150, Espoo, Finland \\ ${ }^{2}$ Laboratory of Carbon NanoMaterials, Department of Physics, Kemerovo State University, Kemerovo 650043, Russia \\ ${ }^{3}$ Laboratory of Physics, Helsinki University of Technology, Otakaari 1 M, 02150, Espoo, Finland \\ ${ }^{4}$ VTT Biotechnology, Biologinkuja 7, 02044, Espoo, Finland \\ Received: 16 January 2009 / Revised: 24 February 2009 / Accepted: 1 March 2009 \\ CTsinghua University Press and Springer-Verlag 2009. This article is published with open access at Springerlink.com
}

\begin{abstract}
We propose a simple method for the efficient and rapid synthesis of one-dimensional hematite $\left(\alpha-\mathrm{Fe}_{2} \mathrm{O}_{3}\right)$ nanostructures based on electrical resistive heating of iron wire under ambient conditions. Typically, 1-5 $\mu \mathrm{m}$ long $\alpha-\mathrm{Fe}_{2} \mathrm{O}_{3}$ nanowires were synthesized on a time scale of seconds at temperatures of around $700{ }^{\circ}$ C. The morphology, structure, and mechanism of formation of the nanowires were studied by scanning and transmission electron microscopies, energy dispersive X-ray spectroscopy, X-ray photoelectron spectroscopy, and Raman techniques. A nanowire growth mechanism based on diffusion of iron ions to the surface through grain boundaries and to the growing wire tip through stacking fault defects and due to surface diffusion is proposed.
\end{abstract}

\section{KEYWORDS}

$\mathrm{Fe}_{2} \mathrm{O}_{3}$, hematite, mechanism, nanowire, synthesis

One-dimensional semiconducting nanostructured oxides in the form of wires have recently attracted tremendous attraction due to their novel properties [1-7]. Hematite $\left(\alpha-\mathrm{Fe}_{2} \mathrm{O}_{3}\right)$ is one of the most interesting and important metal oxides. It is an n-type semiconductor with a band gap of $2.1 \mathrm{eV}$ and has antiferromagnetic properties [8]. Hematite is known to catalyze a number of chemical reactions and due to its low toxicity can be successfully employed in many chemical and biochemical applications [9-12].
In addition, $\alpha-\mathrm{Fe}_{2} \mathrm{O}_{3}$ has many other uses including in nonlinear optics, gas sensors, and as a pigment [13 $-15]$.

The growth of $\alpha-\mathrm{Fe}_{2} \mathrm{O}_{3}$ nanowires (NWs) has been carried out mainly on pure iron foils/plates or powder in a heated and well-controlled environment, i.e., at a certain partial pressure of particular gases or under vacuum conditions [13, 16-22]. Typical time required for the synthesis of a dense NW "forest" by oxidation of pure iron range from hours to a few tens

Address correspondence to A. Nasibulin, albert.nasibulin@hut.fi; E. Kauppinen, esko.kauppinen@tkk.fi 
of hours. Recently, a new way of rapid NW synthesis by direct plasma oxidation of bulk materials was proposed [23, 24]. However, this method is complicated, since it requires both vacuum conditions and equipment to create plasma under controlled conditions. Here, we propose a very simple method, which does not require any complicated equipment or a controlled atmosphere, since the synthesis can be carried out using a basic DC power supply (such as a car battery or a set of household batteries) under ambient conditions; the process of NW formation is very rapid, with a typical growth time of a few seconds, and with a very little energy consumption. The method is described in detail in the Electronic Supplementary Material (ESM).

In spite of intensive research into one-dimensional structures of metal oxides in particular and NWs in general, our understanding of the mechanisms of their formation and growth is still incomplete. Our method affords the possibility to investigation the NW growth. The morphology, structure, and nanowire formation were examined by scanning and transmission electron microscopies (SEM and TEM), energy dispersive X-ray spectroscopy (EDX), X-ray photoelectron spectroscopy (XPS), and Raman techniques.

Iron oxide NWs were grown by resistive heating of iron wire (99.99\% and $99.5 \%$, Goodfellow) with a diameter of $0.25 \mathrm{~mm}$ under ambient laboratory conditions. The growth was carried out by applying a potential difference of $2.7-7.8 \mathrm{~V}$ (with a current of $2.5-2.6 \mathrm{~A}$ ) to $5.8-15.0 \mathrm{~cm}$ long Fe wires. It is important to note that the synthesis can be easily controlled by observing the color of the wire and by varying the applied heating power (see the ESM). SEM observation of the wire after the synthesis of the reddish material revealed that the wire was completely covered by NWs (Fig. 1). The NWs had a sword-like shape, i.e., they are belt-like structures, which are thicker at the base and thinner at the end. EDX analysis confirmed that the NWs consisted of oxygen and iron (see ESM). A bright-field TEM image (Fig. 2(a)) showed that typical length of the NWs was about 1-5 $\mu \mathrm{m}$. High-resolution TEM images (with their Fourier transform shown as an inset) were consistent with the rhombohedral crystal structure of $\alpha-\mathrm{Fe}_{2} \mathrm{O}_{3}$ (Fig. 2(b) and ESM). A tilt series of electron diffraction patterns from an individual NW (Fig. 2(c)) obtained by rotating the wire around its axis at $0^{\circ}$, $32.5^{\circ}$, and $50.2^{\circ}$ were indexed as zone axes of [001] (Fig. 2(d)), [-111] (Fig. 2(e)), and [-221] (Fig. 2(f)) of rhombohedral $\alpha-\mathrm{Fe}_{2} \mathrm{O}_{3}$. Thereby, based on the TEM analysis it can be concluded that the NWs grow in the [110] direction, which is in agreement with the literature [21]. Detailed TEM investigations showed that the NWs are single-crystalline with stacking faults oriented along the wires (see ESM).

In order to confirm the formation of an $\alpha-\mathrm{Fe}_{2} \mathrm{O}_{3}$ phase we carried out XPS measurements. The binding energy scale was referenced to the characteristic carbon 1s binding energy of $285 \mathrm{eV}$ (Fig. 3(a)). The Fe $2 \mathrm{p}_{3 / 2}$ maximum was found at approximately $710 \mathrm{eV}$ and the first satellite peak at $719 \mathrm{eV}$ (Fig. 3(b)). The positions of these peaks as well as the shape of the Fe $2 p$ spectrum agree well with those for the $\mathrm{Fe}^{3+}$ state reported in Ref. [25]. The presence of two states of

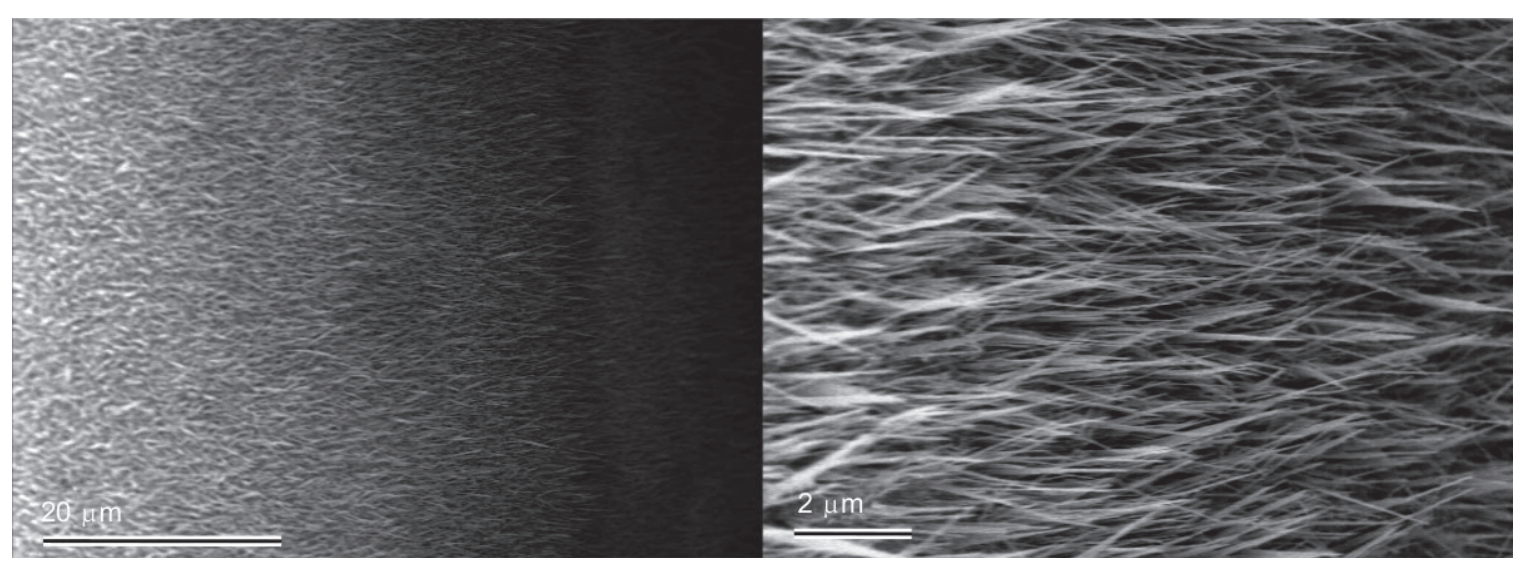

Figure 1 SEM images of the surface of the iron wire after the synthesis 


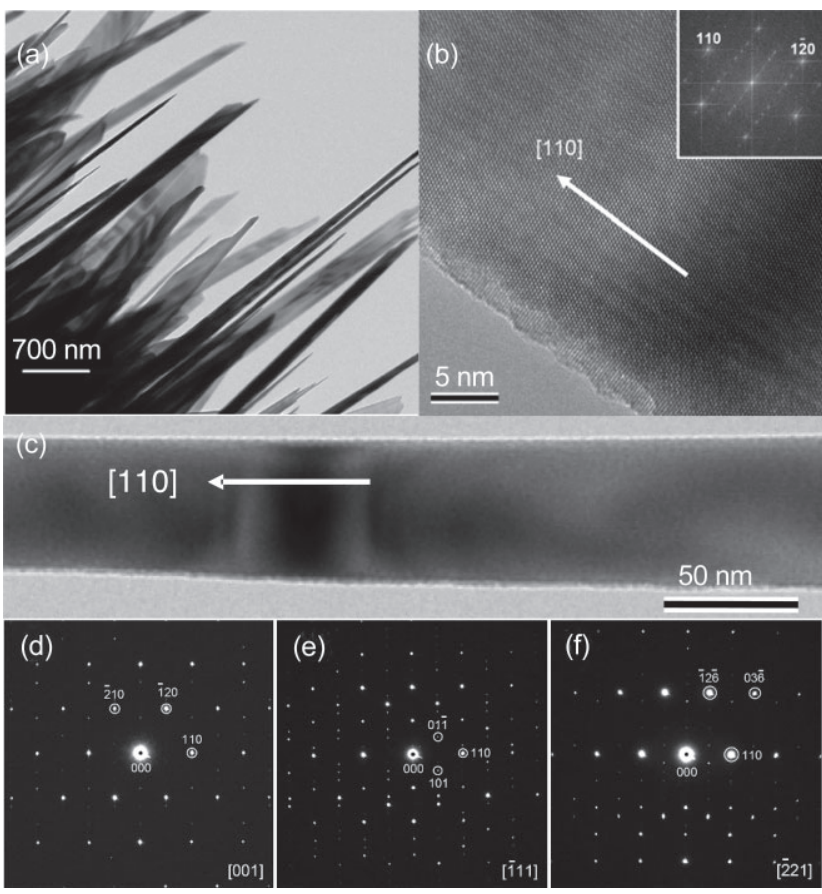

Figure 2 TEM images of NWs at (a) low and (b) high magnifications. The inset in (b) shows the Fourier transform indexed as $\alpha-\mathrm{Fe}_{2} \mathrm{O}_{3}$. (c) TEM image of an individual NW. (d)-(f) A tilt series of electron diffraction patterns obtained by rotating the NW along its axis by (e) $32.5^{\circ}$ and (f) $50.2^{\circ}$ from pattern (d)

oxygen in the samples is shown in Fig. 3(c). The main peak at $529.5 \mathrm{eV}$ most likely corresponds to $\mathrm{O}^{2-}$ in the iron oxide lattice. The second broad feature is shifted by about $2 \mathrm{eV}$ to higher binding energy and can be attributed to $\mathrm{OH}^{-}$or adsorbed oxygen [26]. Thus, the XPS analysis confirmed the formation of a $\mathrm{Fe}_{2} \mathrm{O}_{3}$ phase.

Raman investigations of the cross-section part of the wire revealed the formation of different layers during the NW growth (Figs. 4(a) and 4(b)). The spectra showed that the upper layer of the wire consists of mainly $\alpha-\mathrm{Fe}_{2} \mathrm{O}_{3}$ as can be seen in Fig. 4(c).
In addition to Raman peaks corresponding to $\alpha-\mathrm{Fe}_{2} \mathrm{O}_{3}$ (at 225, 245, 292, 411, 498, 611, and $1323 \mathrm{~cm}^{-1}$ ), a very weak peak of $\mathrm{Fe}_{3} \mathrm{O}_{4}$ at $663 \mathrm{~cm}^{-1}[27,28]$ was also detected in the surface layer of the oxidized wire. The next layer can be clearly distinguished in SEM and optical and SEM images in Figs. 4(a) and 4(b) and was assigned to $\mathrm{Fe}_{3} \mathrm{O}_{4}$ (on the basis of the Raman peaks at 299, 537, and $633 \mathrm{~cm}^{-1}$ in Fig. 4(d)) [28]. This layer was found to be fairly porous. The third layer is about $10 \mu \mathrm{m}$ thick and gives the only peak at $645 \mathrm{~cm}$ ${ }^{-1}$ corresponding to $\mathrm{FeO}$ (Fig. 4(e)). Spectra from the core of the iron wire under the oxide layers, which were peeled off, did not show any Raman signal, which suggests that the core consists of a pure iron phase. These results show that the oxidation state of iron increases from 0 to +3 on going from the core to the upper layer.

As mentioned above, the growth of $\alpha-\mathrm{Fe}_{2} \mathrm{O}_{3} \mathrm{NWs}$ is generally a time-consuming process [13, 16-22]. Our method, based on rapid wire heating from ambient temperature to the optimum synthesis temperature allowed us to determine the maximum NW growth rate. For this purpose, we applied a potential difference to wires (to heat them up to $700{ }^{\circ} \mathrm{C}$ ) for a certain period of time (the growth time). After this time, the wires were rapidly cooled down by switching the power off. Surprisingly, after only $2 \mathrm{~s}$ growth time, $\alpha-\mathrm{Fe}_{2} \mathrm{O}_{3} \mathrm{NWs}$ with a length of about $200 \mathrm{~nm}$ were already found on the surface of the treated wires (see ESM). Thus, it can be concluded that the growth of $\alpha-\mathrm{Fe}_{2} \mathrm{O}_{3} \mathrm{NWs}$ is a rapid process with the growth rate exceeding $100 \mathrm{~nm} / \mathrm{s}$. A very dense NW forest was produced after $40 \mathrm{~s}$ and no significant changes were observed when heating time was further increased. This rapid NW growth is

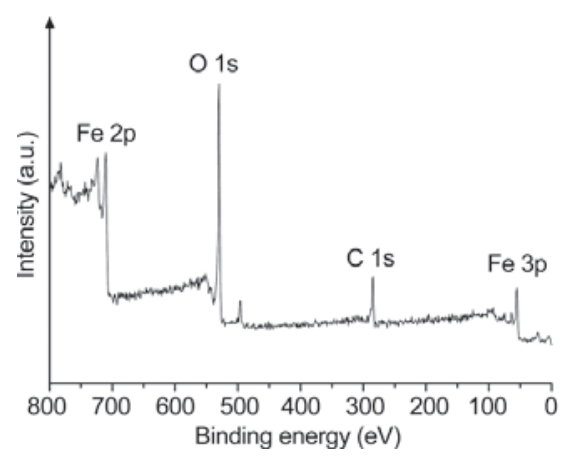

(a)

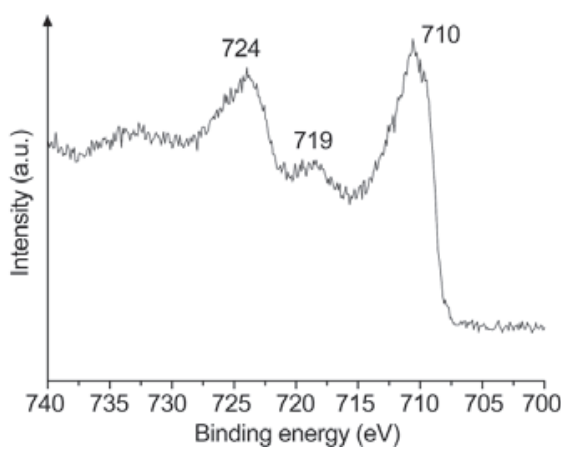

(b)

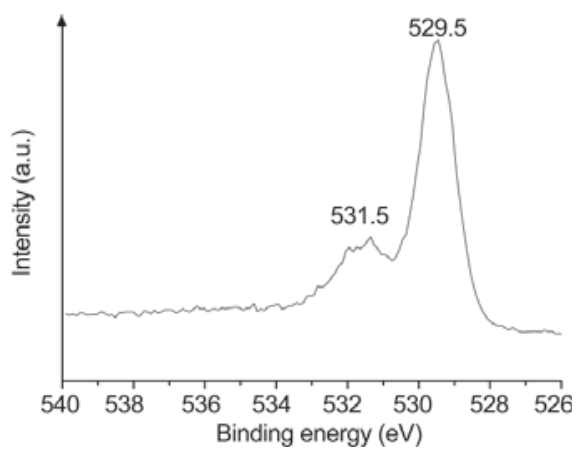

(c)

Figure 3 XPS spectra of $\alpha-\mathrm{Fe}_{2} \mathrm{O}_{3}$ NWs: (a) wide range spectrum; (b) Fe 2p spectrum; (c) O 1s spectrum 


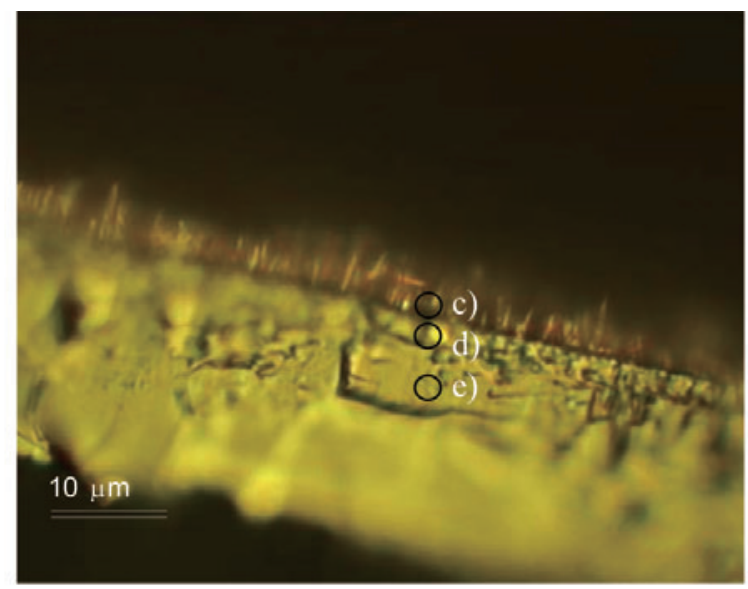

(a)

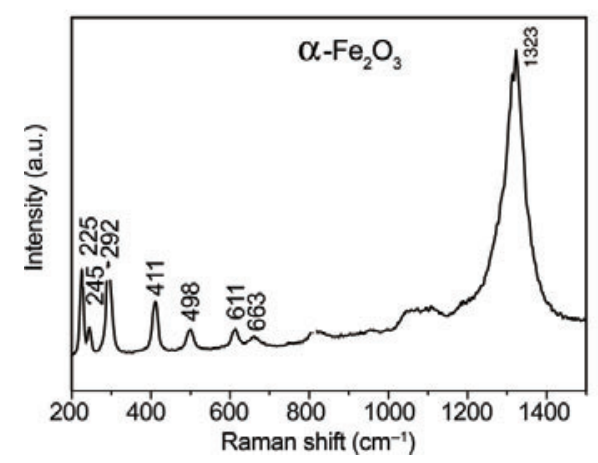

(c)

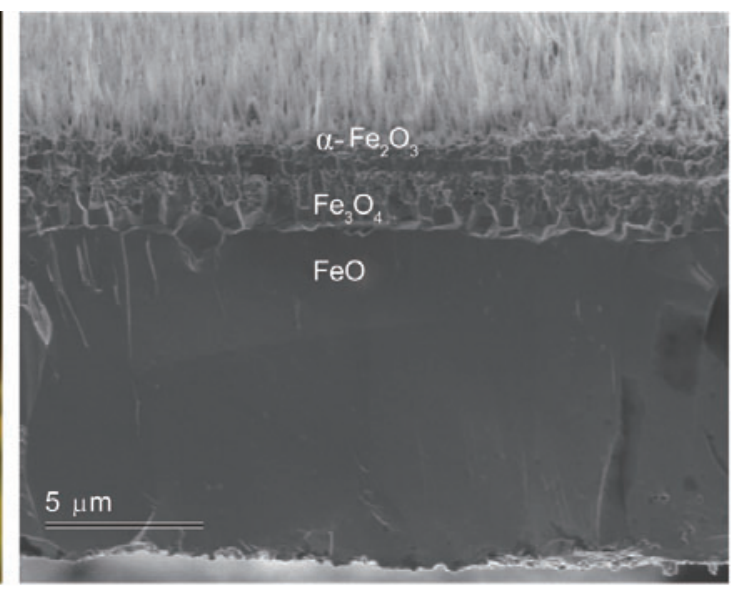

(b)

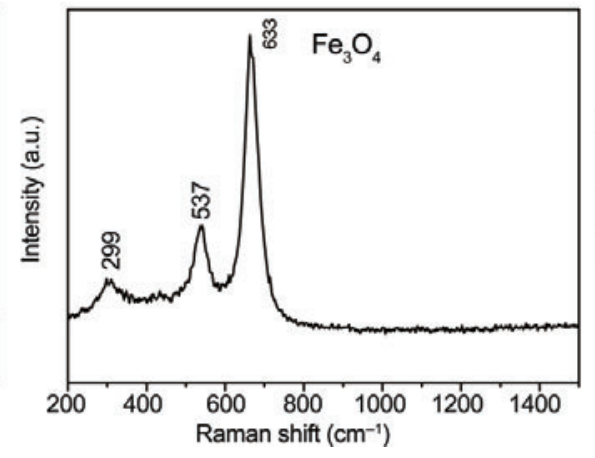

(d)

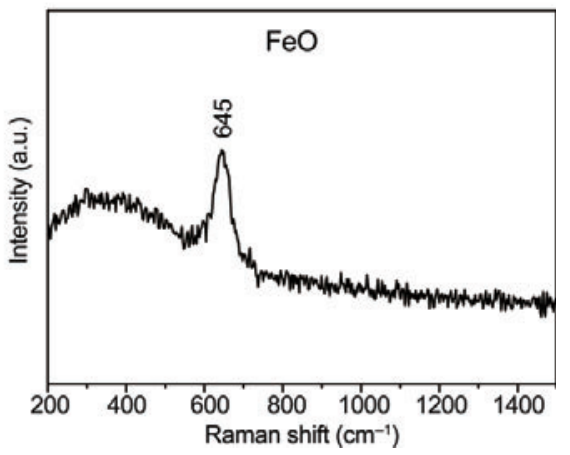

(e)

Figure 4 Iron oxide layers: (a) optical microscope image (circles indicate approximate areas of Raman measurements); (b) SEM image showing different iron oxidation layers. Raman spectra of iron oxide layers from the indicated measurement points: (c) $\alpha$ - $\mathrm{Fe}_{2} \mathrm{O}_{3}$, (d) $\mathrm{Fe}_{3} \mathrm{O}_{4}$, (f) $\mathrm{FeO}$

observed in the temperature "window" from 700 to $720^{\circ} \mathrm{C}$.

The enhanced growth at temperatures of around $700{ }^{\circ} \mathrm{C}$ coincides with the results observed by Takagi [22]. However, in our case the growth rate is about one order of magnitude higher than the maximum rate in an oxygen atmosphere reported by Takagi. This can be explained by the different heating speeds and temperature profiles across the wires: in our method the wire was rapidly heated from below the surface, providing a higher temperature gradient across the wire compared to that obtained with conventional furnace oxidation techniques. Another important reason is the presence of water and $\mathrm{CO}_{2}$ in ambient air, which can increase the rates of formation and growth of NWs [29].

NW growth is usually described by either vapor -solid or vapor-liquid-solid mechanisms [3036]. In our case, the NW synthesis occurred at low temperatures (significantly lower than the melting temperatures of both iron and its oxides) and at negligibly small equilibrium pressures of iron vapor above pure metal or its oxides and therefore cannot be ascribed to any of these mechanisms. NW growth during iron oxidation has also been explained by the stress driven mechanism [13, 17, 20-22], in which a relaxation of the large stress results in NW formation generated by dislocation slips. Substantial stresses are expected to be accumulated on the interface due to structural and density differences [17]. In the stress driven mechanism, it is believed that the upper layer provides a path to release the stress in the form of NWs. However, simple estimations of the density of different oxide layers show that the volume increase in the $\mathrm{FeO}$ layer is $77 \%$ with respect to $\mathrm{Fe}$, the volume of $\mathrm{Fe}_{3} \mathrm{O}_{4}$ shows a $255 \%$ increase with respect to $\mathrm{FeO}$, while the formation of $\mathrm{Fe}_{2} \mathrm{O}_{3}$ is accompanied by a $32 \%$ decrease in the molecular volume. This means that the stress should be mainly accumulated in the $\mathrm{Fe}_{3} \mathrm{O}_{4}$ and $\mathrm{FeO}$ layers and cannot directly affect the 
growth of the NWs.

Figure 5 shows our understanding of the NW formation conditions and a suggested mechanism for their growth on the basis of our experimental results and literature data. The formation of NWs occurs when three layers of iron oxides are gradually formed by oxidation of iron. We believe that the growth of NWs is determined by diffusion processes. The driving force determining the motion of iron and oxide ion species is the potential difference appearing during the wire oxidation process. The electric field strength between iron and $\mathrm{Fe}_{2} \mathrm{O}_{3}$ layers can reach values as large as $10^{6} \mathrm{~V} / \mathrm{cm}$ [37]. It is worth noting that the electric field arising during resistive heating of an iron wire is about six orders of magnitude lower and thereby cannot significantly affect the ion motion across the wire. The iron oxidation process involves iron ion diffusion from the iron wire core to the surface through the iron oxide layers

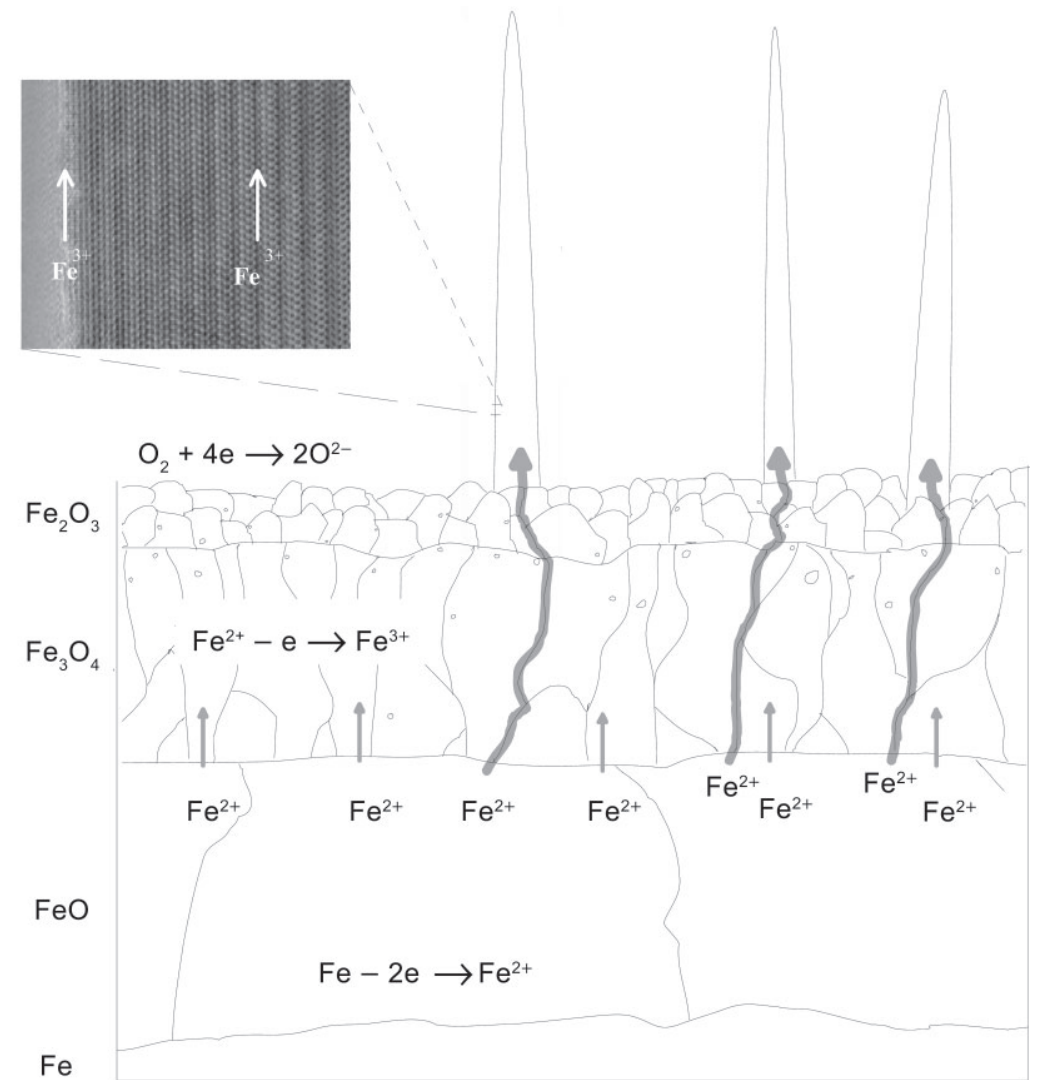

Figure 5 Schematic presentation of the NW growth in ambient air: delivery of iron ions through grain boundaries to the surface and the growth of NWs via diffusion through stacking fault defects in the [110] direction and surface diffusion and diffusion of oxide ions in the opposite direction $[37,38]$. At certain temperatures, grain boundaries in the $\mathrm{FeO}$ and $\mathrm{Fe}_{3} \mathrm{O}_{4}$ layers, likely formed due to the oxidation stress, could be responsible for higher diffusion rates compared to lattice diffusion [38]. In the initial stage, the $\mathrm{Fe}_{2} \mathrm{O}_{3}$ phase might grow in all directions; however, further growth only occurs in the [110] crystallographic direction as this is energetically most favorable [21], involving easier diffusion and favorable stacking. It is worth noting that the presence of stacking faults in the growth direction supports our proposed mechanism, since the diffusion rate is enhanced in crystal defects at elevated temperatures $[39,40]$. Another path for iron ion delivery to the top of the growing NW is surface diffusion. The sword-like shape of the NWs confirms that the growth is determined by a diffusion process from the bottom-where the NWs are thicker-to the top, where they become thinner.

In conclusion, we propose a very simple method based on resistive heating of iron wires under ambient laboratory conditions to synthesize 1-D hematite $\left(\alpha-\mathrm{Fe}_{2} \mathrm{O}_{3}\right)$ nanostructures in the form of NWs with a length of 1-5 $\mu \mathrm{m}$. It was shown that the iron wire after heat treatment consisted of layers of different iron-containing compounds starting from $\mathrm{Fe}$ in the core via $\mathrm{FeO}$ and $\mathrm{Fe}_{3} \mathrm{O}_{4}$ to $\mathrm{Fe}_{2} \mathrm{O}_{3}$ on the surface. The most efficient growth of $\alpha-\mathrm{Fe}_{2} \mathrm{O}_{3}$ with a high density on the surface of the iron wire was found at temperatures of about $700{ }^{\circ} \mathrm{C}$. Formation of NWs was detected even after $2 \mathrm{~s}$. The NW growth rate was estimated to exceed $100 \mathrm{~nm} / \mathrm{s}$, which is about one order of magnitude higher than the maximum rate reported previously. It was found that NWs grew in the [110] crystallographic direction and contained stacking faults along the NW direction. A mechanism of NW growth based on the diffusion of iron ions to the surface of wire through grain boundaries and to the tip of the growing NW through stacking faults and by surface diffusion is proposed. 


\section{Acknowledgements}

The authors thank Dr. Paula Queipo for investigations of the iron oxide NW stability. This work was supported by the Academy of Finland (project numbers 128445 and 128495). P. R. M. acknowledges Finnish National Graduate School in Nanoscience (NGS-NANO). S. D. S. thanks the European Commission for financial support through a Marie Curie Individual Fellowship (MIF1-CT-2005-022110).

Electronic Supplementary Material: Supplementary material is available in the online version of this article at http://dx.doi.org/10.1007/s12274-009-9036-5 and is accessible free of charge. (1) Growth of nanowires; (2) Nanowires: Six years later; (3) TEM investigations of nanowires; (4) Kinetics of nanowire growth.

\section{References}

[1] Li, Y.; Qian, F.; Xiang, J.; Lieber, C. M. Nanowire electronic and optoelectronic devices. Mater. Today 2006, 9, 18-27.

[2] Lu, J. G.; Chang, P.; Fan, Z. Quasi-one-dimensional metal oxide materials-Synthesis, properties and applications. Mater. Sci. Eng. R 2006, 52, 49.

[3] Fang, X.; Zhang, L. One-dimensional ZnS nanomaterials and nanostructures. J. Mater. Sci. Technol. 2006, 22, 721.

[4] Law, M.; Goldberger, J.; Yang, P. Semiconductor nanowires and nanotubes. Ann. Rev. Mater. Res. 2004, 34, 83-122.

[5] Kolasinski, K. W. Current opinion in solid state and materials. Science 2006, 10, 182.

[6] Cao, G.; Liu, D. Template-based synthesis of nanorod, nanowire, and nanotube arrays. Adv. Colloid Interfac. Sci. 2008, 136, 45-64.

[7] Satyanarayana, V. N. T.; Kuchibhatla, A. S.; Karakoti, D. B.; Seal, S. One dimensional nanostructured materials. Prog. Mater. Sci. 2007, 52, 699-691.

[8] Cornell, R. M.; Schwertmann, U. The Iron Oxides; VCH: Weinheim, 1996.

[9] Khedr, M. H.; Bahgat, M.; Nasr, M. I.; Sedeek, E. K. CO decomposition over freshly reduced nanocrystalline $\mathrm{Fe}_{2} \mathrm{O}_{3}$. Colloid. Surfaces A: Physicochem. Eng. Aspects
2007, 302, 517-524.

[10] Chen, J.; Xu, L. N.; Li, W. Y.; Gou, X. L. alpha- $-\mathrm{Fe}_{2} \mathrm{O}_{3}$ nanotubes in gas sensor and lithium-Ion battery applications. Adv. Mater. 2005, 17, 582-586.

[11] Brown, A. S. C.; Hargreaves, J. S. J.; Rijniersce, B. A study of the structural and catalytic effects of sulfation on iron oxide catalysts prepared from goethite and ferrihydrite precursors for methane oxidation. Cat. Lett. 1998, 53, 7-13

[12] Khare, N.; Eggleston, C. M.; Lovelace, D. M.; Boese, S. W. Structural and redox properties of mitochondrial cytochrome c co-sorbed with phosphate on hematite (alpha- $\mathrm{Fe}_{2} \mathrm{O}_{3}$ ) surfaces. J. Colloid Interface Sci. 2006, 303, 404-414.

[13] Srivastava, H.; Tiwari, P.; Srivastava, A. K; Nandedkar, R. V. Growth and characterization of alpha- $\mathrm{Fe}_{2} \mathrm{O}_{3}$ nanowires. J. Appl. Phys. 2007, 102, 054303.

[14] Dong, W. T.; Zhu, C. S. Use of ethylene oxide in the sol-gel synthesis of alpha- $\mathrm{Fe}_{2} \mathrm{O}_{3}$ nanoparticles from Fe(III) salts. J. Mater. Chem. 2002, 12, 1676-1683.

[15] Li, P.; Miser, D. E.; Rabiei, S.; Yadav, R. T.; Hajaligol, $M$. R. The removal of carbon monoxide by iron oxide nanoparticles. Appl. Catal. B Env. 2003, 43, 151-162.

[16] Chueh, Y. -L.; Lai, M. -W.; Liang, J. -Q.; Chou, L. -J.; Wang Z. L. Systematic study of the growth of aligned arrays of alpha- $\mathrm{Fe}_{2} \mathrm{O}_{3}$ and $\mathrm{Fe}_{3} \mathrm{O}_{4}$ nanowires by a vaporsolid process. Adv. Funct. Mater. 2006, 16, 2243-2251.

[17] Zhao, Y. M.; Li, Y. -H.; Ma, R. Z.; Roe, M. J.; McCartney, D. G.; Zhu, Y. Q. Growth and characterization of iron oxide nanorods/nanobelts prepared by a simple iron-water reaction. Small 2006, 2, 422-427.

[18] Qin, F.; Magtoto, N. P.; Garza, M.; Kelber, J. A. Oxide film growth on Fe(111) and scanning tunneling microscopy induced high electric field stress in $\mathrm{Fe}_{2} \mathrm{O}_{3} / \mathrm{Fe}(111)$. Thin Solid Films 2003, 444, 179-188.

[19] Han, Q.; Xu, Y. Y.; Fu, Y. Y.; Zhang, H.; Wang, R. M.; Wang, T. M.; Chen, Z. Y. Defects and growing mechanisms of $\alpha-\mathrm{Fe}_{2} \mathrm{O}_{3}$ nanowires. Chem. Phys. Lett. 2006, 431, 100-103.

[20] Fu, Y. Y.; Wang, R. M.; Xu, J.; Chen, J.; Yan, Y.; Narlikar, A. V. Zhang, $\mathrm{H}$. Synthesis of large arrays of aligned $\alpha-\mathrm{Fe}_{2} \mathrm{O}_{3}$ nanowires. Chem. Phys. Lett. 2003, 379, 373-379.

[21] Wen, X.; Wang, S.; Ding, Y.; Wang, Z. L.; Yang, S. Controlled growth of large-area, uniform, vertically aligned arrays of $\alpha-\mathrm{Fe}_{2} \mathrm{O}_{3}$ nanobelts and nanowires. J. Phys. Chem. B 2005, 109, 215-220.

[22] Takagi, R. Growth of oxide whiskers on metals at high 
temperature. J. Phys. Soc. Japan 1957, 12, 1212-1218.

[23] Mozetic, M.; Cvelbar, U.; Sunkara, M. K.; Vaddiraju, S. A method for the rapid synthesis of large ouantities of metal oxide nanowires at low temperatures. Adv. Mater. 2005, 17, 2138-2142.

[24] Cvelbar, U.; Chen, Z.; Sunkara, M. K.; Mozetic, M. Spontaneous growth of superstructure $\alpha-\mathrm{Fe}_{2} \mathrm{O}_{3}$ nanowire and nanobelt arrays in reactive oxygen Plasma. Small 2008, 4, 1610-1614.

[25] Aronniemi, M.; Sainio, J.; Lahtinen, J. Chemical state quantification of iron and chromium oxides using XPS: The effect of the background subtraction method. Surface Sci. 2005, 578, 108-123.

[26] Kawabe, T.; Shimomura, S.; Karasuda, T.; Tabata, K.; Suzuki, E.; Yamaguchi, Y. Photoemission study of dissociatively adsorbed methane on a pre-oxidized $\mathrm{SnO}_{2}$ thin film. Surf. Sci. 2000, 448, 101-107.

[27] de Faria, D. L. A.; Lopes, F. N. Heated goethite and natural hematite: Can Raman spectroscopy be used to differentiate them? Vib. Spectrosc. 2007, 45,117-121.

[28] de Faria, D. L. A.; Silva, V.; de Oliveira, M. T. Raman microspectroscopy of some iron oxides and oxyhydroxides. J. Raman Spectroscopy 1997, 28, 873.

[30] Sato, Y.; Young, D. J. High-temperature corrosion of Iron at $900{ }^{\circ} \mathrm{C}$ in atmospheres containing $\mathrm{HCl}$ and $\mathrm{H}_{2} \mathrm{O}$. Oxid. Met. 2001, 55, 243-260.

[31] Grosvenor, A. P.; Kobe, B. A.; Mclntyre, N. S. Examination of the oxidation of iron by oxygen using X-ray photoelectron spectroscopy and QUASES (TM). Surface Sci. 2004, 565, 151-162.

[32] Pan, Z. W.; Dai, Z. R.; Wang, Z. L. Nanobelts of semiconducting oxides. Science 2001, 291, 1947-1949.

[33] Morales, A. M.; Lieber, C. M. A laser ablation method for the synthesis of crystalline semiconductor nanowires. Science 1998, 279, 208-211.

[34] Wagner, R. S.; Ellis, W. C. Vapor-liquid-solid mechanism of single crystal growth. Appl. Phys. Lett. 1964, 4, 89-90.

[35] Chueh, Y. L.; Lai, M. -W.; Liang, J. -Q.; Chou, L. -J.; Wang Z. L. Systematic study of the growth of aligned arrays of $\alpha-\mathrm{Fe}_{2} \mathrm{O}_{3}$ and $\mathrm{Fe}_{3} \mathrm{O}_{4}$ nanowires by a vapor-solid process. Adv. Funct. Mater. 2006, 16, 2243-2251.

[36] Givargizov, E. I. Fundamental aspects of VLS growth. J. Cryst. Growth 1975, 31, 20-30.

[39] Raynaud, G. M.; Rapp, R. A. In situ observation of whiskers, pyramids and pits during the high-temperature oxidation of metals. Oxid. Met. 1984, 21, 89-102.

[40] Hiralal, P.; Unalan, H. E.; Wijayantha, K. G. U.; Kursumovic, A.; JefFerson, D .; MacManus-Driscoll, J. L.; Amaratunga, G. A. J. Growth and process conditions of aligned and patternable films of iron(III) oxide nanowires by thermal oxidation of iron. Nanotechnology 2008, 19, 455608.

[29] Saunders, S. R. J.; Monteiro, M.; Rizzo F. The oxidation behaviour of metals and alloys at high temperatures in atmospheres containing water vapour: A review. Progress Mater. Sci. 2008, 53, 775-837.

[37] Young, D. High Temperature Oxidation and Corrosion of Metals; Elsevier Corrosion Series: Oxford, 2008.

[38] Voss, D. A.; Butler, E. P.; Mitchell, T. E. The growth of hematite blades during the high-temperature oxidation of iron. Metall. Trans. A 1982, 13A, 929-935. 